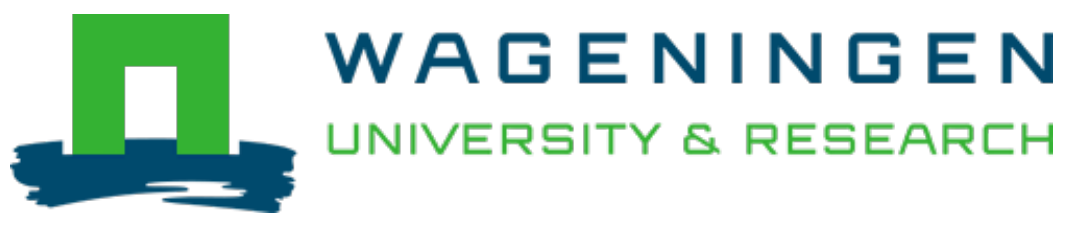

\title{
FT-IR Spectroscopy with chemometrics for rapid detection of wheat flour adulteration with barley flour
}

Journal für Verbraucherschutz und Lebensmittelsicherheit

Arslan, F.N.; Akin, G.; Karuk Elmas, Şükriye Nihan; Üner, B.; Yilmaz, I. et al

https://doi.org/10.1007/s00003-019-01267-9

This publication is made publicly available in the institutional repository of Wageningen University and Research, under the terms of article $25 \mathrm{fa}$ of the Dutch Copyright Act, also known as the Amendment Taverne. This has been done with explicit consent by the author.

Article 25 fa states that the author of a short scientific work funded either wholly or partially by Dutch public funds is entitled to make that work publicly available for no consideration following a reasonable period of time after the work was first published, provided that clear reference is made to the source of the first publication of the work.

This publication is distributed under The Association of Universities in the Netherlands (VSNU) 'Article $25 \mathrm{fa}$ implementation' project. In this project research outputs of researchers employed by Dutch Universities that comply with the legal requirements of Article $25 \mathrm{fa}$ of the Dutch Copyright Act are distributed online and free of cost or other barriers in institutional repositories. Research outputs are distributed six months after their first online publication in the original published version and with proper attribution to the source of the original publication.

You are permitted to download and use the publication for personal purposes. All rights remain with the author(s) and / or copyright owner(s) of this work. Any use of the publication or parts of it other than authorised under article $25 \mathrm{fa}$ of the Dutch Copyright act is prohibited. Wageningen University \& Research and the author(s) of this publication shall not be held responsible or liable for any damages resulting from your (re)use of this publication.

For questions regarding the public availability of this publication please contact openscience.library@wur.nl 


\title{
FT-IR spectroscopy with chemometrics for rapid detection of wheat flour adulteration with barley flour
}

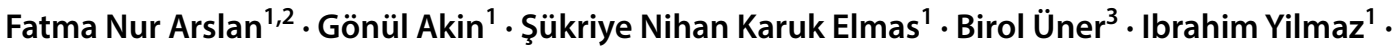 \\ Hans-Gerd Janssen ${ }^{2,4} \cdot$ Adnan Kenar ${ }^{5}$
}

Received: 20 July 2019 / Revised: 1 December 2019 / Accepted: 16 December 2019 / Published online: 25 February 2020

(c) Bundesamt für Verbraucherschutz und Lebensmittelsicherheit (BVL) 2020

\begin{abstract}
The quality of wheat flour (WF) is among the highest of cereal flours and therefore, it is one of the most expensive flours for manufacturing food products. In developing countries, adulteration of WF by mixing up with lower price cereal flours is often seen. Hence, the classification and determination of the adulteration quantity in WF is of great interest. The aim of this research was to evaluate the feasibility of FT-IR spectroscopy and multivariate data analysis methods for the detection of adulteration of WF with the most likely adulterant barley flour (BF). For this purpose, 20 pure cereal flours and 120 flour blends were analyzed using FT-IR spectroscopy with chemometrics. The spectra were collected in the region of $4000-450 \mathrm{~cm}^{-1}$ and up to 15 wavenumber regions corresponding to peaks of flour constituents were selected. The classification limit value of soft independent modeling of class analogies for detection of BF added to WF was better than $1 \%$. Additionally, $98.25 \%$ of the flours were correctly classified by linear discriminant analysis. Partial least squares regression was adopted to construct a model to quantify the adulteration level. The root mean square error of calibration for sample calibration associated forecast parameters was $0.34-1.34 \%$ and the root mean square error of cross validation was $0.36-1.50 \%$. Thus, the BF adulterant could be detected down to approximately $0.30 \%$.
\end{abstract}

Keywords Adulteration $\cdot$ Spectroscopy $\cdot$ Chemometrics $\cdot$ Cereal $\cdot$ Flour

Electronic supplementary material The online version of this article (https://doi.org/10.1007/s00003-019-01267-9) contains supplementary material, which is available to authorized users.

Fatma Nur Arslan

arslanfatmanur@gmail.com

1 Department of Chemistry, Faculty of Science, University of Karamanoglu Mehmetbey, 70100 Karaman, Turkey

2 Analytical-Chemistry Group, Van’t Hoff Institute for Molecular Sciences, University of Amsterdam, Science Park 904, 1098 XH Amsterdam, The Netherlands

3 Department of Metallurgy and Material Engineering, Faculty of Engineering, University of Karamanoglu Mehmetbey, 70100 Karaman, Turkey

4 Department of Compositional Analytical Sciences, Unilever Research Laboratory, Vlaardingen, The Netherlands

5 Department of Chemistry, Faculty of Science, University of Ankara, 06100 Ankara, Turkey

\section{Introduction}

The authentication of agro-food products is of great importance as clearly evidenced by the large number of major adulteration events being revealed in the last decade. Fraudulent practices occurred with a wide variety of agricultural products including vegetable oils, milk products and fruit juices, but also cereal products (Lohumi et al. 2015; Su and Sun 2017). In developing countries, most adulteration in cereals happens in WF (Cocchi et al. 2006; Amir et al. 2013; González-Martín et al. 2014; Ziegler et al. 2016; Hong et al. 2017). In these countries, WF is one of the most important components of the human diet thanks to its unique nutritional and physical properties. In addition to being a rich source of carbohydrates, it contains a suite of valuable bioactive components (Cocchi et al. 2006; Amir et al. 2013; González-Martín et al. 2014; Ziegler et al. 2016; Hong et al. 2017). In comparison to other common cereal flours, WF also has superior features for the manufacture of many food products. However, because of its high cost, wheat flour is a target for adulteration with cost-effective and poor-quality 
flours (González-Martín et al. 2014; Lohumi et al. 2015; Ziegler et al. 2016; Su and Sun 2017). Apart from consumer fraud, adulteration of WF could also pose serious health threats such as human cancers, celiac disease etc. (Guo et al. 2015; Czaja et al. 2016). Hence, there is a need for rapid, reliable, and environmentally friendly methods for WF authentication.

Recently, various spectroscopic methods with chemometrics models have been evaluated as methods to determine the quality and authenticity of cereal products. These include techniques like Fourier transform infrared (Ellis et al. 2012; González-Martín et al. 2014; Cozzolino 2015), Raman (Ellis et al. 2012; González-Martín et al. 2014; Cozzolino 2015; Lohumi et al. 2015; Su and Sun 2017), hyperspectral imaging (Lohumi et al. 2015; Su and Sun 2017) and nuclear magnetic resonance (NMR) spectroscopy (Ellis et al. 2012; Hong et al. 2017). These methods have rapid and non-destructive detection characteristics for food quality analysis, as well as their capability to investigate foodstuffs with minimum sample preparation. They lack many disadvantages of conventional methods such as long analysis time, sample handling errors and use of chemicals. In the range of spectroscopic methods applied for quality control of cereal products such as bread (Guo et al. 2015; Ziegler et al. 2016), grain (Cocchi et al. 2006; Amir et al. 2013; González-Martín et al. 2014) and flour (Cocchi et al. 2004; Ferrão and Davanzo 2005; Georget and Belton 2006; Dong and Sun 2013; Hernández et al. 2014; Guo et al. 2015; Sujka et al. 2017), especially FT-IR has significant potential. FT-IR combined with chemometrics has been successfully applied in several food studies. For example, Guo et al. (2015) studied the applicability of FT-IR in the mid-infrared region to identify fluorescent brighteners in wheat flour (Guo et al. 2015). A partial least squares regression (PLSR) model combined with FT-IR and FT-Raman was found to give satisfactory prediction ranges $\left(R^{2}>0.980\right)$ for quantification of fluorescence brighteners. Czaja et al. (2016) reported multivariate data analysis of FT-IR and FT-Raman data to establish the gluten content in WF. The developed PCA and PLSR models presented high accuracy values for $\mathrm{R}^{2} \mathrm{CV}(0.818-0.925)$ and the root mean square error of cross validation (RMSECV) (3.46-4.83\%) (Czaja et al. 2016). Su and Sun (2016) determined organic spelt flour adulteration with organic WF, non-organic rye and spelt flours. PLSR and multiple linear regression (MLR) models were developed, simplified and successfully applied in several studies after the selection of the optimal wavenumbers. Based on the selected wavenumbers, the basic PLSR performed better than MLR with a mean $\mathrm{R}^{2}$ of 0.96 (Su and Sun 2016). Sujka et al. (2017) constructed robust statistical models allowing classification of various flours based on the content of proteins, lipids, moisture and ash. Moreover, the nutritional profiles including calorific values of unknown flours could obtain rapidly and reliably (Sujka et al. 2017). So far, however, WF adulteration and the possibility of using spectroscopic methods for its detection have not yet been studied. As far as we know, the previous studies did not involve the selection of characteristic bands in FT-IR spectra with different chemometrics analyses for the analysis of WF adulteration with barley flours (BFs).

In the present study, the feasibility of FT-IR spectroscopy with chemometrics for the detection of adulteration of WF with cheaper BF samples was investigated qualitatively and quantitatively. This includes also the selection of the most informative spectral bands. The applicability of FT-IR with chemometrics for the differentiation between pure wheat flours and other flours was also investigated. Principle component analysis (PCA), linear discriminant analysis (LDA), hierarchical cluster analysis (HCA) and soft independent modeling of class analogies (SIMCA) models were developed for the classification and differentiation of WF and other flours as well as of their blends.

\section{Material and methods}

\subsection{Experimental design for sample preparation}

Cereal seeds of wheat, barley, oat, rye and triticale were supplied from various regions in Turkey. All samples [wheat seeds (Ahmet Aga, Karahan, Konya-2002, Bozkir and Taner), barley seeds (Beysehir-98, Larende, Karatay-94, Konevi-98, Kiral-97), oat seeds (Dirilis, Faikbey, Kahraman, Seydisehir, Yeniceri), rye seed (Aslim-94) and triticale seeds (Alperbey, Melez, Mikham, Tatlicak), harvested in 2018] were donated by the Turkish Ministry of Food, Agriculture and Livestock, Bahri Dagdas International Agricultural Research Institute (Konya, Turkey). To remove surface contaminations, each seed sample was washed with ultra-pure water and seeds were then dried before being milled.

A laboratory scale Quadrumat Junior mill (Brabender GmbH and Co. KG, Duisburg, Germany) equipped with an $80 \mu \mathrm{m}$ sieve was used to produce pure and homogenous flour samples. A total of 20 flours were produced as different pure samples; 5 flours of wheat cultivars, 5 flours of barley cultivars, 5 flours of oat cultivars, 1 rye flour, and 4 flours of triticale cultivars. Flour blends were arranged by mixing four diverse cultivars of WFs ( $n=4$; WF-1 to 4$)$ and three diverse cultivars of BFs ( $\mathrm{n}=3$; $\mathrm{BF}-1$ to 3$)$. Homogenization was performed by mixing in an agate mortar for $10 \mathrm{~min}$. The WF samples were adulterated with BF at nine levels: $1-50 \%$ (Table 1). The description of the sample preparation procedure and their codes are given in Table 1. 
Table 1 Preparation of pure and adulterated flour samples

\begin{tabular}{|c|c|c|}
\hline \multicolumn{3}{|c|}{ Sample sets } \\
\hline \multicolumn{3}{|c|}{$\begin{array}{l}\text { Adulterated wheat flour samples } \\
\text { with barley flours }\end{array}$} \\
\hline 1 st & 12 samples & WFs (WF-1 to 4 ) adulterated with $0 \%$ of 3 different BFs (BF-1 to 3 ) \\
\hline 2 nd & 12 samples & WFs (WF-1 to 4 ) adulterated with $1 \%$ of 3 different BFs (BF-1 to 3 ) \\
\hline $3 \mathrm{rd}$ & 12 samples & WFs (WF- 1 to 4 ) adulterated with $2 \%$ of 3 different BFs (BF-1 to 3 ) \\
\hline 4 th & 12 samples & WFs (WF-1 to 4 ) adulterated with $5 \%$ of 3 different BFs (BF-1 to 3 ) \\
\hline 5 th & 12 samples & WFs (WF-1 to 4 ) adulterated with $10 \%$ of 3 different BFs (BF-1 to 3 ) \\
\hline 6 th & 12 samples & WFs (WF-1 to 4 ) adulterated with $15 \%$ of 3 different BFs (BF-1 to 3 ) \\
\hline 7 th & 12 samples & WFs (WF-1 to 4 ) adulterated with $20 \%$ of 3 different BFs (BF-1 to 3 ) \\
\hline 8 th & 12 samples & WFs (WF-1 to 4 ) adulterated with $30 \%$ of 3 different BFs (BF-1 to 3 ) \\
\hline 9th & 12 samples & WFs (WF-1 to 4 ) adulterated with $40 \%$ of 3 different BFs (BF-1 to 3 ) \\
\hline 10th & 12 samples & WFs (WF-1 to 4 ) adulterated with $50 \%$ of 3 different BFs (BF-1 to 3 ) \\
\hline \multicolumn{3}{|c|}{ Pure wheat flours and other flour samples } \\
\hline 11 th & 20 samples & $\begin{array}{l}5 \text { different flour cultivars of wheat (WF-1 to 5) } \\
5 \text { different flour cultivars of barley (BF-1 to } 5) \\
5 \text { different flour cultivars of oat (OF-1 to } 5) \\
1 \text { flour cultivar of rye (RF-1) } \\
4 \text { different flour cultivars of triticale (TF-1 to 4) }\end{array}$ \\
\hline Total & \multicolumn{2}{|c|}{140 samples (120 flour blends +20 pure flours) } \\
\hline
\end{tabular}

$W F$ wheat flour, $B F$ barley flour, $O F$ oat flour, $R F$ rye flour, $T F$ triticale flour

\subsection{FT-IR spectroscopy analysis}

For FT-IR spectroscopic measurements, a Perkin-Elmer Spectrum 100 model infrared spectrometer (Perkin Elmer, Waltham, MA, USA) was utilized. Background corrected spectra of flour samples were acquired as 64 scans with a resolution of $4 \mathrm{~cm}^{-1}$ with a wavenumber range from 450 to $4000 \mathrm{~cm}^{-1}$. All spectroscopic experiments were performed in four replicates. The spectra were collected as percentage transmittance from constant amounts of flour embedded in potassium bromide $(\mathrm{KBr})$ pellets. It is well known that the advantages of pellets are spectral reproducibility and the ability to deal with relatively difficult or limited-mass samples. Besides, solid samples such as flour samples typically have to be diluted with the IR-inactive good stored/dried $\mathrm{KBr}$ chemical and pressed into the $\mathrm{KBr}$-pellet procedure.

In the first stage of FT-IR spectroscopic measurements, the results of attenuated total reflectance (ATR) and $\mathrm{KBr}$ pellet procedures were tested and compared. To reduce the influence of undesired factors on the spectral variability and to obtain reproducible results, different factors related to the sample preparation procedure were also checked. Moreover, to test the reproducibility of the pellet preparation, the pellets for each flour blends and pure flours were prepared three times. Under the same conditions, the results of $\mathrm{KBr}$ pellet technique were more acceptable and reproducible. $\mathrm{KBr}$ pellets were prepared by mixing $300 \mathrm{mg}$ of $\mathrm{KBr}$ with $1 \mathrm{mg}$ of flour sample and pressing the powder in a pellet forming system at 10 tons pressure. For each flour blend and pure flour samples, pellets were prepared in triplicate to test the reproducibility of the pellet preparation with the aim to reduce the effect of undesired factors on the spectral changeability. Pressed pellets were placed in a measuring holder and then placed in the measuring chamber.

\subsection{Chemometrics and software}

Chemometrics analysis of the obtained spectral data was performed with PCA, LDA, HCA, SIMCA and PLSR analyses by using Unscrambler ${ }^{\circledR} \mathrm{X} 10.4$ Software (CAMO software, Oslo, Norway) after the evaluation of the raw spectral data with Octave Chemometrics Software (Version 4.2.1, GNU General Public License). PCA is a dimension reduction technique that generates a few new variables, the so-called principal components (PCs), from linear combinations of the original variables. This unsupervised exploratory technique is generally applied prior to any other more complex discrimination or prediction method (Karuk Elmas et al. 2019). The qualitative pattern method, HCA, was based on creating tree-structured clusters of samples, according to distances between their properties. HCA starts by finding the closest pair of cases and merges them to form a cluster. Until all the cases are in one cluster, the algorithm continues one step at a time, joining pairs of cases, pairs of clusters, or a case with a cluster. These steps are presented as a dendrogram which represents the similarity clustering between samples. The method is defined as hierarchical since once two cases are 
joined in a cluster they remain joined (Kenar et al. 2019). The supervised class modeling technique, SIMCA, is generated by computing two independent PC models and plotting the residual distances of samples of each two classes one versus the other. Coomans plots from SIMCA analyses are useful tools for visualizing the results of the classification analysis (Gurdeniz et al. 2008; Rohman et al. 2014; Borràs et al. 2015; Karuk Elmas et al. 2019). LDA is another supervised classification technique in which the number of categories and the samples belonging to each category are previously defined. The criterion of LDA for selection of latent variables maximizes the differences between categories and minimizes the variances within categories. Classification results of the model were presented in terms of recognition and prediction abilities. Recognition ability symbolizes a percentage of successfully classified samples in the "training set" and prediction ability represents a percentage of correctly classified samples in the "test set" by using the model developed during the training step (Arslan and Çăglar 2019; Kenar et al. 2019).

First derivative Savitzky-Golay smoothing (Deng et al. 2012) and SNV (Savitzky and Golay 1964) pre-treatments were applied to the FT-IR spectral data to correct the noise, possible baseline shifts or global intensity changes. In the PLSR analysis, spectral data were divided into two groups as "calibration data set" ( $75 \%$ of samples) to create the model and "validation data set" ( $25 \%$ of samples) to test the validity of the model. For the established prediction models, full cross-validation was performed with as many subsets as were included in the calibration matrix (leave-one-out method). 1080 spectra (90 flour samples, 3 pellets each, 4 spectra per pellet) were employed for calibration, and 360 spectra were employed as the validation set. To assess the analytical performance of the developed PLSR models, the multiple quality descriptors and statistical values [slope, offset, R-Square $\left(\mathrm{R}^{2}\right)$, RMSECV and root mean square error of calibration (RMSEC)] were calculated.

\subsection{Physico-chemical parameters from reference methods}

The contents of protein, crude fat, carbohydrates, ash and moisture for both the pure and the blend flours were determined using official methods. Protein content (\%) of the samples was determined according to the American Association of Cereal Chemists (AACC) standard method 46-13.01 (Micro-Kjeldahl method) (American Association of Cereal Chemists 1989). Crude fat contents were measured using the AACC method 30-25.01, a method based on Soxhlet extraction using petroleum ether as the solvent. Moisture (\%) and ash (\%) contents were determined using oven drying and ashing according to AACC method 44-15.02 and method 08-01.01, respectively. The total carbohydrate contents were calculated using the difference method, i.e. total carbohydrate is $100-$ (moisture $\%+$ ash $\%+$ crude fat $\%$ + crude protein\%) (Akubor and Badifu 2004). The analyses were performed in triplicate for each sample and the mean values with statistical parameters were calculated.

\section{Results and discussion}

\subsection{FT-IR spectra and reference method data of flour samples}

FT-IR spectra of the pure WF and the other flour samples (barley, rye, triticale and oat) are presented in Fig. 1. The spectra of the different pure flours are similar and herein, it is complicated to distinguish WF from the other flours analyzed. Most of the spectral bands and relevant wavenumber ranges have already been assigned (Table 2). The basic bands in the flour spectra shown in Fig. 1 are the stretching vibration of the $\mathrm{O}-\mathrm{H}$ bond in the range of $3600-3200 \mathrm{~cm}^{-1}$, the stretching vibrations of aromatic and aliphatic $\mathrm{C}-\mathrm{H}$ bonds in the range of $3100-3000 \mathrm{~cm}^{-1}$ and $3000-2800 \mathrm{~cm}^{-1}$, respectively, and the unique pattern in the so-called fingerprint region, the region between 1500 and $450 \mathrm{~cm}^{-1}$. In the case of the analyzed flour samples, although no large differences were observed, small yet significant differences occur in the regions between 4000 and $3025 \mathrm{~cm}^{-1}, 3025$ and $2800 \mathrm{~cm}^{-1}$ and in the 1500 and $450 \mathrm{~cm}^{-1}$ fingerprint region (Cocchi et al. 2004; Guo et al. 2015; Sujka et al. 2017). Especially relevant are the narrow bands centered around $2850 \mathrm{~cm}^{-1}$ and the $2200-1400 \mathrm{~cm}^{-1}$ range which have been identified by authors as being characteristic of lipid and protein constituents of several flour samples, respectively. The narrow bands around $2850 \mathrm{~cm}^{-1}$ predominantly reflect symmetric stretching vibration modes of the $\mathrm{C}-\mathrm{H}$ bond in alkylic $-\mathrm{CH}_{2}$ and $-\mathrm{CH}_{3}$ groups and are primarily because of (bound) lipids, as also is the peak of carboxyl $\mathrm{C}=\mathrm{O}$ at $1745 \mathrm{~cm}^{-1}$. The two strong bands at about 1650 and $1540 \mathrm{~cm}^{-1}$, are most likely related to combinations of vibration modes of the amino acids in the proteins, the amide-I and II groups, respectively (Cocchi et al. 2004; Su and Sun 2017).

The FT-IR spectra obtained for the pure and blended flours were quite similar (Supplementary Material 1, Fig. S1), and differentiation of the analyzed flours was challenging. As expected, the main spectral bands only contain general information on the molecular skeleton and functional groups of flours, which are largely identical for all samples. However, individual bands do not provide information useful for classification or for determination of the degree of purity or level of adulteration of the flour samples. Therefore, chemometrics classification models using the full or specific region's spectra could help to circumvent this drawback (see Sect. 3.3). To that end, 15 


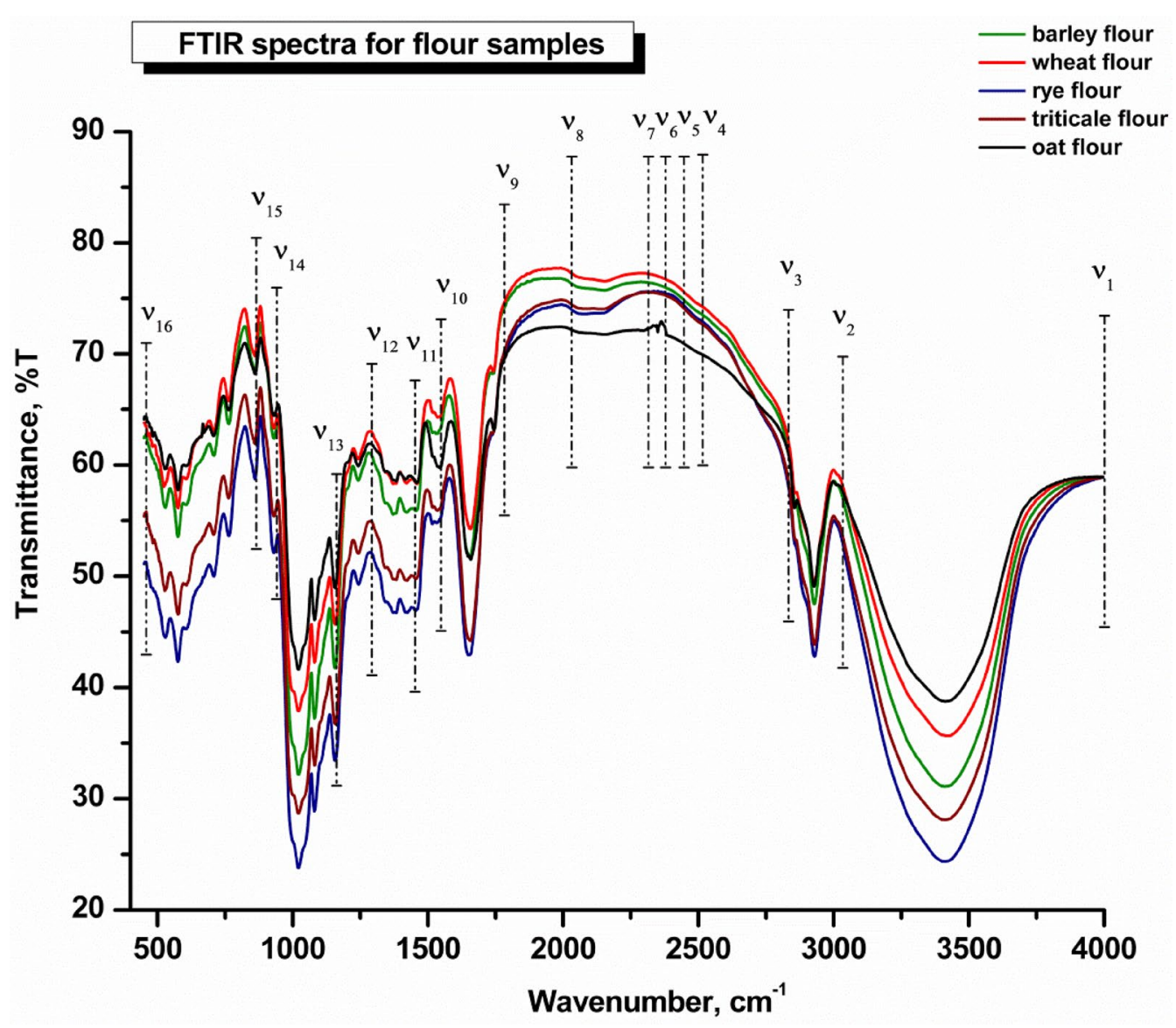

Fig. 1 FT-IR spectra for flour samples and main transmittance bands $\left(v_{\mathrm{x}}-\mathrm{v}_{\mathrm{y}}\right)\left[\mathrm{v}_{1}-\mathrm{v}_{2} ; 4000-3025 \mathrm{~cm}^{-1}, \mathrm{v}_{2}-\mathrm{v}_{3} ; 3025-2800 \mathrm{~cm}^{-1}, \mathrm{v}_{3}-\mathrm{v}_{4}\right.$; $2800-2390 \mathrm{~cm}^{-1}, v_{4}-v_{5} ; 2390-2350 \mathrm{~cm}^{-1}, v_{5}-v_{6} ; 2350-2315 \mathrm{~cm}^{-1}$, $\mathrm{v}_{6}-\mathrm{v}_{7} ; 2315-2290 \mathrm{~cm}^{-1}, \mathrm{v}_{7}-\mathrm{v}_{8} ; 2290-2000 \mathrm{~cm}^{-1}, \mathrm{v}_{8}-\mathrm{v}_{9} ; 2000-$ $1835 \mathrm{~cm}^{-1}, v_{9}-v_{10} ; 1835-1585 \mathrm{~cm}^{-1}, v_{10}-v_{11} ; 1585-1495 \mathrm{~cm}^{-1}$,

spectral regions $\left(v_{x}-v_{y}\right)$ were selected (Table 2) based on literature information: the ranges $3025-2800 \mathrm{~cm}^{-1}$, $1835-1585 \mathrm{~cm}^{-1}, 1585-1495 \mathrm{~cm}^{-1}$ and $1495-1280 \mathrm{~cm}^{-1}$, containing information on the proteins present (Cocchi et al. 2004; Ferrão and Davanzo 2005; Georget and Belton 2006; Guo et al. 2015; Sujka et al. 2017), the ranges $4000-3025 \mathrm{~cm}^{-1}, 1835-1585 \mathrm{~cm}^{-1}, 1280-1220 \mathrm{~cm}^{-1}$ and $950-885 \mathrm{~cm}^{-1}$ containing information on the fats (Su and Sun 2017; Sujka et al. 2017) and the ranges $4000-3025 \mathrm{~cm}^{-1}$ and $1280-1220 \mathrm{~cm}^{-1}$ related to moisture (Moroi et al. 2011; Su and Sun 2017; Sujka et al. 2017). The humidity of each flour sample showed no significant differences, and this could be seen at $4000-3025 \mathrm{~cm}^{-1}$ and $1280-1220 \mathrm{~cm}^{-1}$ (Fig. 1). The selected wavenumber regions were also evaluated to assess their ability to detect WF adulteration using multivariate data analyses.

The results and ANOVA statistics of the standard flour analyses (protein, crude fat, carbohydrates, ash, moisture $\mathrm{v}_{11}-\mathrm{v}_{12} ; 1495-1280 \mathrm{~cm}^{-1}, \mathrm{v}_{12}-\mathrm{v}_{13} ; 1280-1220 \mathrm{~cm}^{-1}, \mathrm{v}_{13}-\mathrm{v}_{14} ; 1220$ $\left.950 \mathrm{~cm}^{-1}, v_{14}-\mathrm{v}_{15} ; 950-885 \mathrm{~cm}^{-1}, \mathrm{v}_{15}-\mathrm{v}_{16} ; 885-450 \mathrm{~cm}^{-1}\right]$. [WF wheat flour, $B F$ barley flour, $O F$ oat flour, $R F$ rye flour, $T F$ triticale flour]

contents) determined using the AACC reference methods are presented in Table S1 and S2 (Supplementary Materials 7 and 8 ).

\subsection{PCA, LDA, HCA and SIMCA based on spectra of the full wavenumber region}

In order to discriminate the WF from other flours and from the adulterated wheat flour, PCA, SIMCA, LDA and HCA models were created using the spectral data of full region $\left(4000-450 \mathrm{~cm}^{-1}\right)$ as input. Prior to multivariate data analysis, SNV and first derivative Savitzky-Golay smoothing pretreatments were performed (Fig. S1b, Supplementary Material 1). 
Table 2 FT-IR spectral regions selected as predictor candidates for multivariate data analysis, and assignments to vibrational transitions for flour samples

\begin{tabular}{|c|c|c|c|c|}
\hline $\begin{array}{l}\text { Stretch- } \\
\text { ing range, } \\
\text { ox-oy }\end{array}$ & Wave number range, $\mathrm{cm}^{-1}$ & Functional group & Mode of vibration & References \\
\hline $\mathrm{v}_{1}-\mathrm{v}_{2}$ & $4000-3025 \mathrm{~cm}^{-1}$ & $\delta(\mathrm{O}-\mathrm{H})$ & Stretching vibration & $\begin{array}{l}\text { Czaja et al. (2016), Sujka et al. } \\
\text { (2017), Wang et al. (2014) }\end{array}$ \\
\hline $\mathrm{v}_{2}-\mathrm{v}_{3}$ & $3025-2800 \mathrm{~cm}^{-1}$ & $\delta(\mathrm{C}-\mathrm{H}), \delta(\mathrm{N}-\mathrm{H})$ & Stretching vibration & $\begin{array}{l}\text { Czaja et al. (2016), Sujka et al. } \\
\text { (2017) }\end{array}$ \\
\hline $\mathrm{v}_{3}-\mathrm{v}_{4}$ & $2800-2390 \mathrm{~cm}^{-1}$ & $\delta(\mathrm{C}-\mathrm{H})$ & Stretching vibration & $\begin{array}{l}\text { Cocchi et al. (2004), Sujka et al. } \\
\text { (2017) }\end{array}$ \\
\hline $\mathrm{v}_{4}-\mathrm{v}_{5}$ & $2390-2350 \mathrm{~cm}^{-1}$ & $\delta(\mathrm{C}-\mathrm{H})$ & Stretching vibration & $\begin{array}{l}\text { Su and Sun (2017), Sujka et al. } \\
\text { (2017) }\end{array}$ \\
\hline $\mathrm{v}_{5}-\mathrm{v}_{6}$ & $2350-2315 \mathrm{~cm}^{-1}$ & $\delta(\mathrm{C}-\mathrm{H}), \delta(\mathrm{CCH})$ & Stretching vibration & $\begin{array}{l}\text { Su and Sun (2017), Sujka et al. } \\
\text { (2017) }\end{array}$ \\
\hline $\mathrm{v}_{6}-\mathrm{v}_{7}$ & $2315-2290 \mathrm{~cm}^{-1}$ & $\delta(\mathrm{C}-\mathrm{H}), \delta(\mathrm{CCH})$ & Stretching vibration & $\begin{array}{l}\text { Su and Sun (2017), Sujka et al. } \\
\text { (2017) }\end{array}$ \\
\hline $\mathrm{v}_{7}-\mathrm{v}_{8}$ & $2290-2000 \mathrm{~cm}^{-1}$ & $\delta(\mathrm{C}-\mathrm{H}), \delta(\mathrm{CCH})$ & Stretching vibration & $\begin{array}{l}\text { Cocchi et al. (2004), Sujka et al. } \\
\text { (2017) }\end{array}$ \\
\hline$v_{8}-v_{9}$ & $2000-1835 \mathrm{~cm}^{-1}$ & $\delta(\mathrm{C}-\mathrm{H})$ & Stretching vibration & $\begin{array}{l}\text { Su and Sun (2017), Sujka et al. } \\
\text { (2017) }\end{array}$ \\
\hline $\mathrm{v}_{9}-\mathrm{v}_{10}$ & $1835-1585 \mathrm{~cm}^{-1}$ & $\begin{array}{c}\beta \text {-Sheet of amide } \mathrm{I}, \delta(\mathrm{COH}) \\
\delta(\mathrm{CCH}), \delta(\mathrm{OCH}), \nu(\mathrm{C}-\mathrm{O})\end{array}$ & $\begin{array}{l}\text { Stretching and bending vibra- } \\
\text { tion }\end{array}$ & $\begin{array}{l}\text { Cocchi et al. (2004), Czaja et al. } \\
(2016) \text {, Guo et al. (2015), Sujka } \\
\text { et al. (2017) }\end{array}$ \\
\hline $\mathrm{v}_{10}-\mathrm{v}_{11}$ & $1585-1495 \mathrm{~cm}^{-1}$ & $\beta$-Sheet of amide II & & $\begin{array}{l}\text { Cocchi et al. (2004), Guo et al. } \\
\text { (2015) }\end{array}$ \\
\hline$v_{11}-v_{12}$ & $1495-1280 \mathrm{~cm}^{-1}$ & $\delta(\mathrm{C}-\mathrm{H}), \delta(\mathrm{N}-\mathrm{H}), \nu(\mathrm{C}-\mathrm{H})$ & $\begin{array}{l}\text { Stretching and bending vibra- } \\
\text { tion }\end{array}$ & $\begin{array}{l}\text { Cocchi et al. (2004), Guo et al. } \\
\text { (2015) }\end{array}$ \\
\hline$v_{12}-v_{13}$ & $1280-1220 \mathrm{~cm}^{-1}$ & $\begin{array}{l}\beta \text {-Sheet of amide III, } \delta(\mathrm{N}-\mathrm{H}) \text {, } \\
\nu(\mathrm{C}-\mathrm{H})\end{array}$ & $\begin{array}{l}\text { Stretching and bending vibra- } \\
\text { tion }\end{array}$ & $\begin{array}{l}\text { Kaddour et al. (2008), Guo et al. } \\
\text { (2015) }\end{array}$ \\
\hline $\mathrm{v}_{13}-\mathrm{v}_{14}$ & $1220-950 \mathrm{~cm}^{-1}$ & $\nu(\mathrm{C}-\mathrm{O}), \nu(\mathrm{C}-\mathrm{C})$ & Bending vibration & $\begin{array}{l}\text { Kaddour et al. (2008), Carbonaro } \\
\text { et al. (2008), Cozzolino et al. } \\
\text { (2013), Guo et al. (2015) }\end{array}$ \\
\hline $\mathrm{v}_{14}-\mathrm{v}_{15}$ & $950-885 \mathrm{~cm}^{-1}$ & $\begin{array}{l}\delta(\mathrm{COH}), \delta(\mathrm{CCH}), \delta(\mathrm{OCH}), \\
\quad \nu(\mathrm{C}-\mathrm{O})\end{array}$ & $\begin{array}{l}\text { Stretching and bending vibra- } \\
\text { tion }\end{array}$ & $\begin{array}{l}\text { Cozzolino et al. (2013), Su and } \\
\text { Sun (2017) }\end{array}$ \\
\hline $\mathrm{v}_{15}-\mathrm{v}_{16}$ & $885-450 \mathrm{~cm}^{-1}$ & $\delta(\mathrm{COH}), \delta(\mathrm{CCH}), \delta(\mathrm{OCH})$ & Stretching vibration & $\begin{array}{l}\text { Cozzolino et al. (2013), Guo et al. } \\
\text { (2015), Su and Sun (2017) }\end{array}$ \\
\hline
\end{tabular}

$\nu$ stretching vibration, $\delta$ bending

\subsubsection{Classification modeling by PCA}

The first applied method was PCA, which uses a combination of the original variables to project them in a space of less dimensions while protecting the general unpredictability (Hernández et al. 2014; Borràs et al. 2015). The score plot generated from the full spectral data of the pure flours is given in Fig. 2a. This plot shows that all types of flours are well discriminated from WF, however one type of WF is located very close to barley, rye and triticale flours, their eigenvalues were $99 \%(\mathrm{PC} 1=91 \%, \mathrm{PC} 2=8 \%$ ) and $92 \%(\mathrm{PC} 1=91 \%, \mathrm{PC} 3=1 \%)$, respectively. The discrimination seen in this model is most likely clarified by the dissimilarities of the composition and contents of the main ingredients in flour samples. The contents of protein, crude fat, carbohydrates, ash and moisture for both the pure and the blend flours were determined using official methods, and the differences between different samples were statistically evaluated with ANOVA. In general, ANOVA test results confirmed that the means are significantly different at the 0.05 level (Table S1 and S2, Supplementary Materials 7 and 8).

\subsubsection{Discrimination modeling by LDA}

Another important supervised chemometrics analysis is LDA. The criterion in LDA for selection of variables is to maximize the differences between categories while 
(a)

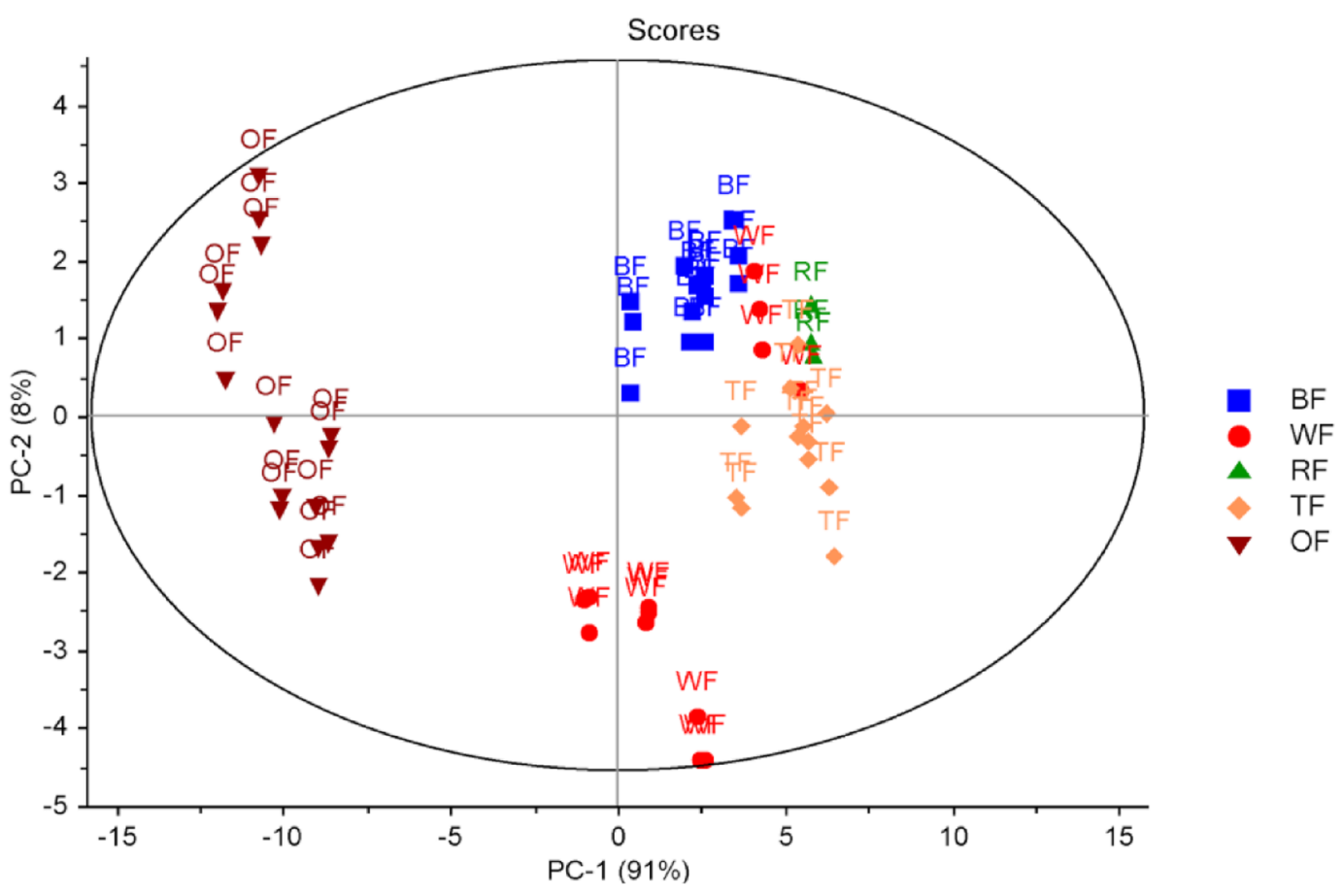

(b)

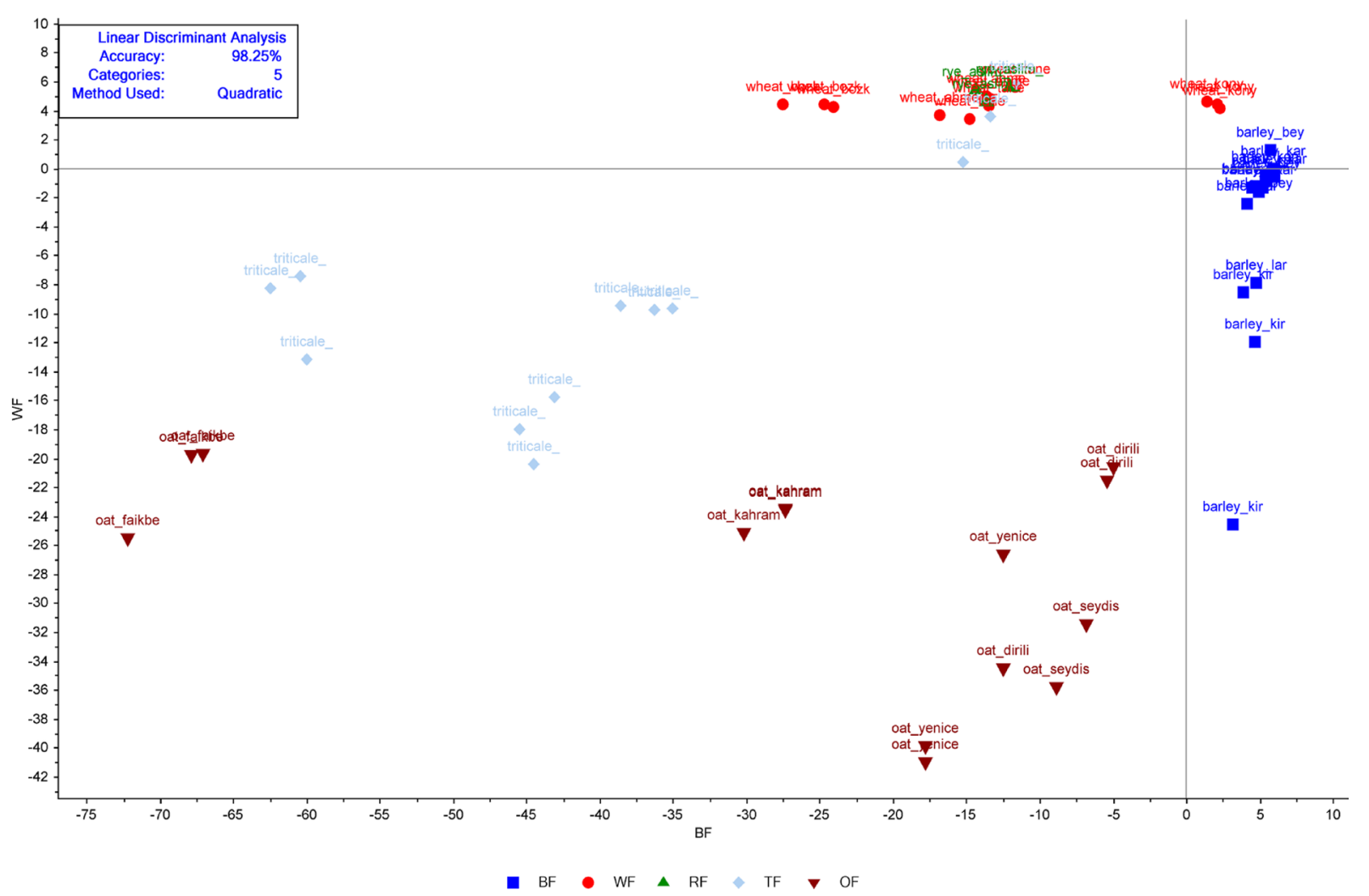

Fig. 2 a PCA and b LDA plots for WF and other cereal flours. SIMCA plots for $\mathbf{c}$ pure wheat flour relative to the other flours and d pure wheat flours and pure barley flours, using the $4000-450 \mathrm{~cm}^{-1}$ data. [ $W F$ wheat flour, $B F$ barley flour, $O F$ oat flour, $R F$ rye flour,
$T F$ triticale flour, $P C$ principle component, $P C A$ principle component analysis, SIMCA soft independent modeling of class analogies, $L D A$ linear discriminant analysis] 
(c)

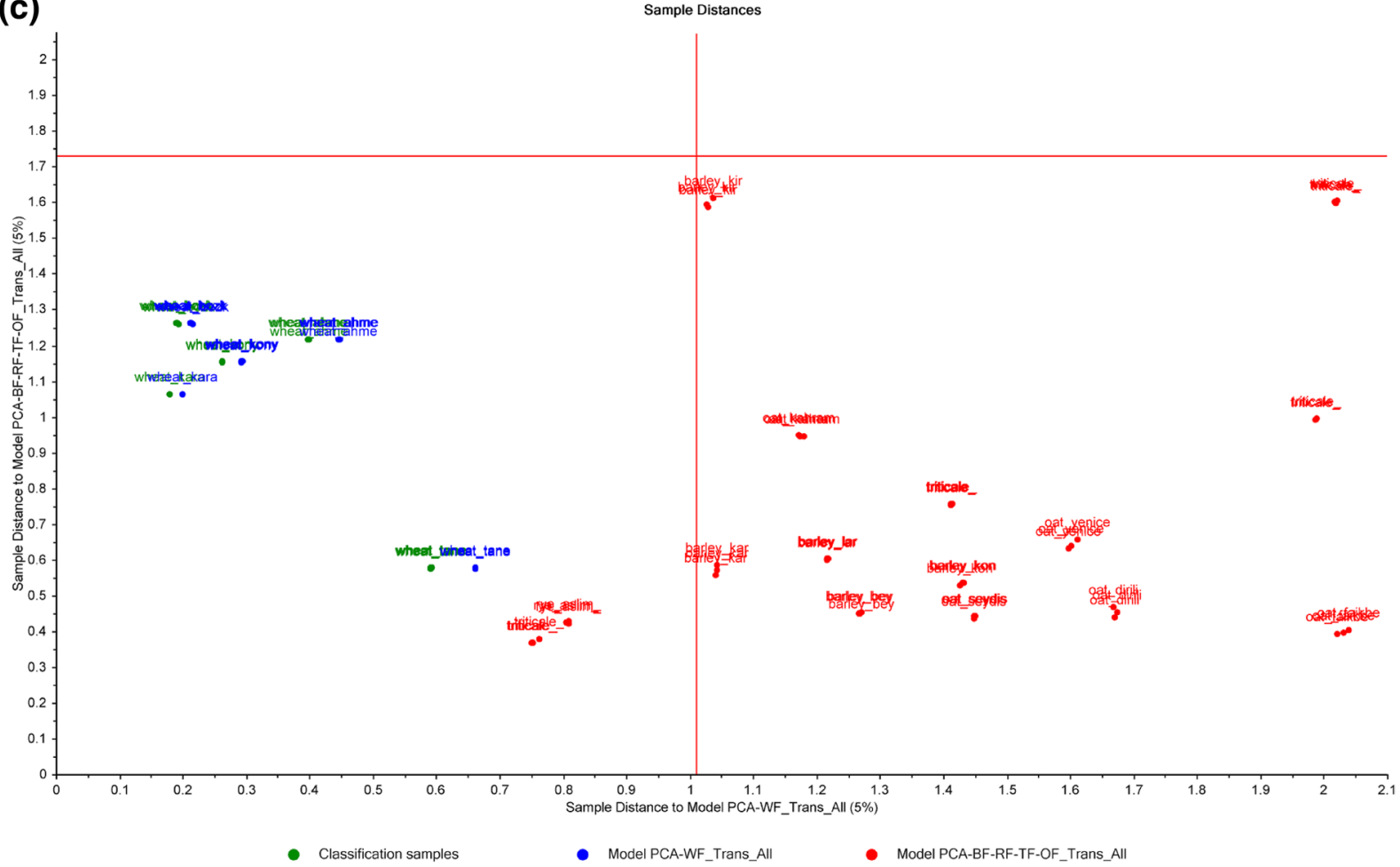

(d)

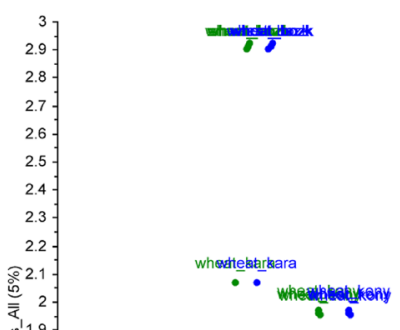

Sample Distances

on

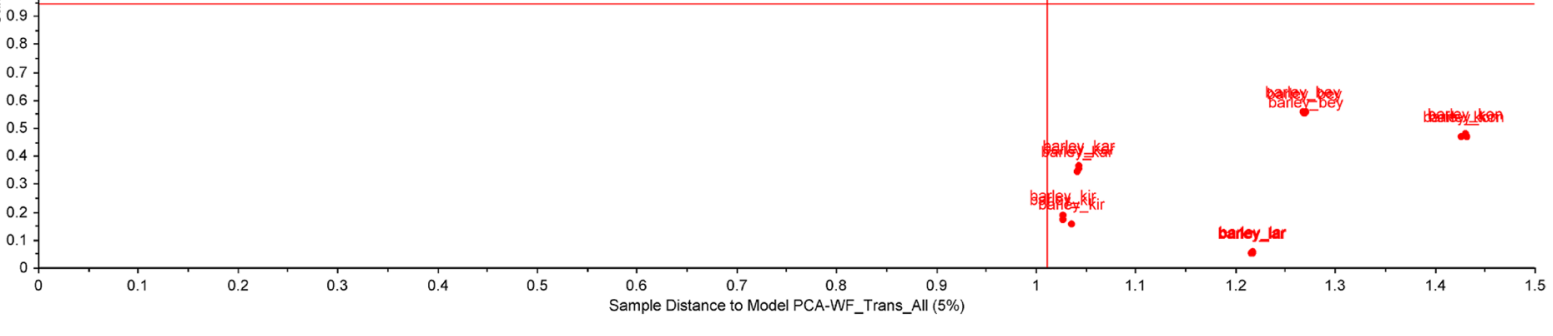

- Classification samples

- Model PCA-WF_Trans_All - Model PCA-BF_Trans_All

Fig. 2 (continued) 
simultaneously minimizing the variances within the categories (Saucedo-Hernández et al. 2011; Borràs et al. 2015). LDA models were built with five types of flours (predictors) using only the most informative wavenumbers as described above. Figure $2 b$ represents the LDA plot of the pure WFs and the other pure flour samples obtained using a quadratic model. In this figure, the good results for discrimination of WF samples from other pure samples were obtained by LDA models. A total of $98.25 \%$ of the samples studied were properly discriminated in a cross-validation. One sample of WF was observed to deviate in the PCA. For this reason, the sample was used as a test case for the LDA. In this model, the WF-Karahan sample was classified as BF. When the other flour samples were defined as a "training set" in the confusion matrix of LDA, all of them were correctly classified (Table S3, Supplementary Material 9). The confusion matrix collects the outputs of the LDA classification model and is the initial step to judge the classification performance. It is a square matrix with dimensions $G \times G$, where $G$ is the number of classes. A column was added to collect the number of not assigned samples for each class. Each element $n_{g k}$ represents the number of samples belonging to class $g$ and assigned to class $k$. Confusion matrix entries on the main diagonal represent the number of correct class assignations, while off-diagonal entries represent classification errors (Ballabio and Consonni 2013).

\subsubsection{Cluster modeling by HCA}

The spectra recorded at wavenumber $4000-450 \mathrm{~cm}^{-1}$ were constructed to check the similarity or dissimilarity of the various flours via HCA. The HCA method clusters the samples without any prior information of the class membership on the basis of a similarity marker (relative distance) and a merger rule that joins similar samples into clusters (Fragaki et al. 2005; Borràs et al. 2015). Figure 3 presents the dendrogram for the classification of the samples as obtained from the HCA. The dendrogram shows that clear clusters were obtained based on the binding distances of the different types of flours allowing the diverse types of samples to be successfully differentiated from each other (Table S4, Supplementary Material 10).

\subsubsection{Classification modeling SIMCA}

A final classification method considered for the discrimination of WFs from other flours was the supervised classification method SIMCA (Fig. 2c, d; Fig. S2, Supplemen-

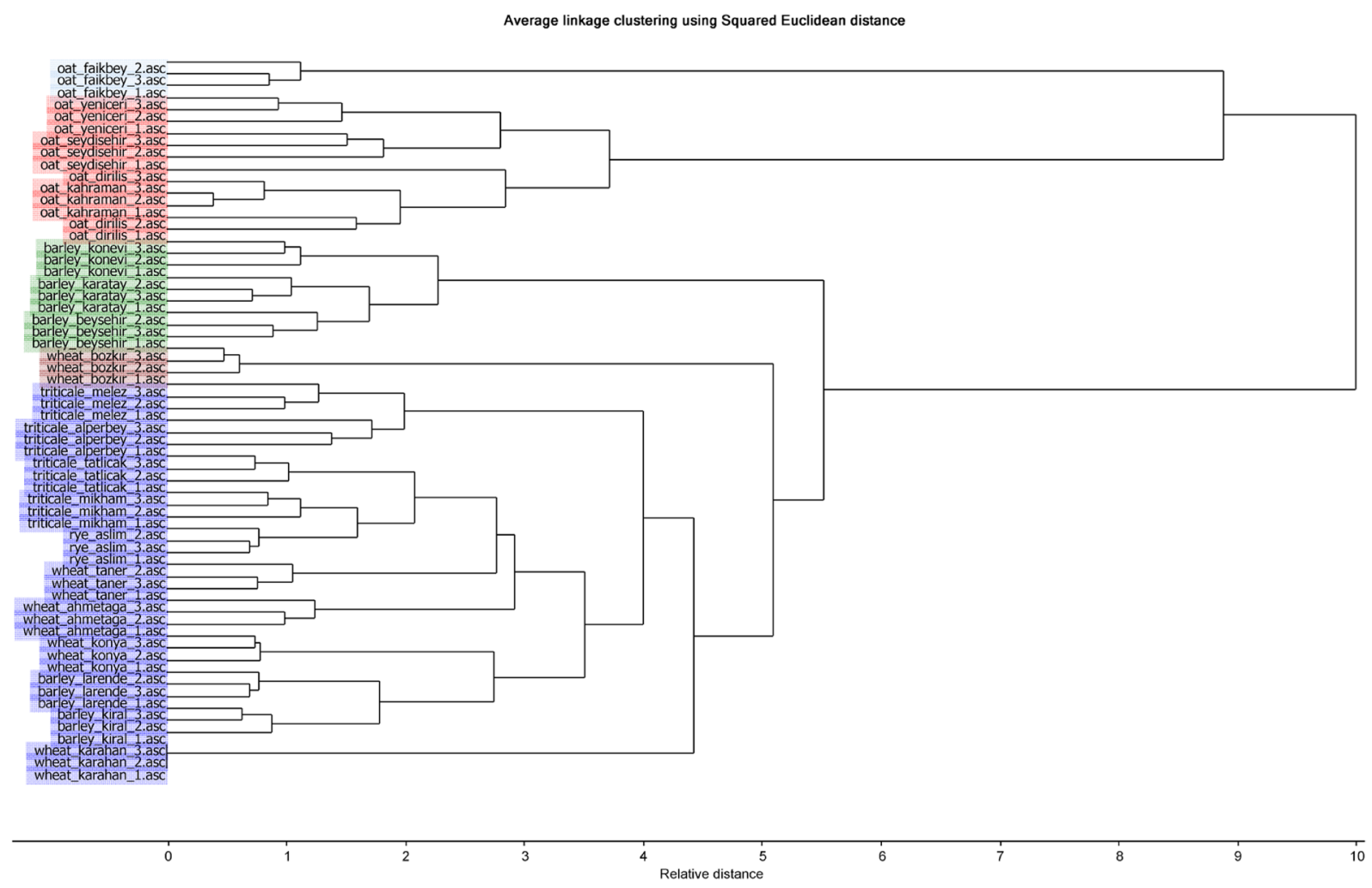

Fig. 3 HCA dendrogram of pure WFs and the other cereal flours. [HCA hierarchical cluster analysis]

tary Material 2). SIMCA was performed using full region 
data, and Coomans plots with 5\% significance level were obtained from these analyses (Gurdeniz et al. 2008; Borràs et al. 2015). To construct Coomans plot, PCA analyses are performed for each group separately and two set models are produced against each other with a specific critical level. If a sample has a interval to the corresponding centre of critical level exceeding the critical distance, it is considered an outlier and is rejected from the definite group (Gurdeniz et al. 2008; Borràs et al. 2015). The SIMCA models consist of two main constituents: pure WFs or other pure flours (Fig. 2c), or pure WFs and pure BFs (Fig. 2d). The latter is cheap adulterant flour and a likely candidate for adulterant use. It is clear from Fig. 2c, d that the WFs and flour samples are not well separated. Especially the separation of WFs from rye flours is difficult. Fortunately, however, the pure WFs are well separated from the most likely adulterant BF. This means that no pure wheat sample or a barley flour samples were incorrectly located into the mistaken classes. SIMCA were also carried out using the full region spectra to distinguish pure WFs from WF adulterated with BFs. The resulting plots are presented in Fig. S3 (Supplementary Material 3). The limit for detection of BF content in WF was below $1 \%$. Therefore, the full FT-IR spectra could be highly valuable for the estimation of WF adulteration. To identify the performance power of SIMCA, the distances between PCA used for constructing SIMCA is also presented in Table S5 (Supplementary Material 11).

\subsection{SIMCA based on spectra of the specific wavenumber regions}

The main constituents of flours determining the FT-IR spectrum are proteins, fats, free fatty acids, carbohydrates, minerals and moisture (Cocchi et al. 2004; Cozzolino 2015; Hong et al. 2017; Su and Sun 2017). Because these main ingredients are present in all flours, the total FT-IR spectra are very similar and specific information is easily lost in the overall picture. Therefore, only multivariate classification models using 15 specific spectral regions defined in literature were considered (Table 2). Models were built using the ten most informative regions. For proteins, the spectral regions $3025-2800 \mathrm{~cm}^{-1}, 1834-1583 \mathrm{~cm}^{-1}, 1583-1494 \mathrm{~cm}^{-1}$, and 1494-1280 $\mathrm{cm}^{-1}$ were considered, for lipids the ranges of $3846-3027 \mathrm{~cm}^{-1}, 1834-1583 \mathrm{~cm}^{-1}, 1279-1221 \mathrm{~cm}^{-1}$ and $952-886 \mathrm{~cm}^{-1}$ and for moisture the spectral ranges of 3846-3027 $\mathrm{cm}^{-1}$ and 1279-1221 $\mathrm{cm}^{-1}$ (Cozzolino 2015; Su and Sun 2017; Sujka et al. 2017). In this study, the combined spectral regions were used to discriminate pure WF from the other pure flour as well as from adulterated WF.

In the first part of the chemometrics, SIMCA was constructed for the discrimination of pure WF from pure BF and for discrimination of pure WF from the other pure flours using a selection of different spectral regions (Fig.
S4, Supplementary Material 4). The Coomans plots demonstrate that the best discrimination of pure WF from barley flours is obtained at $4000-3025 \mathrm{~cm}^{-1}, 3025-2800 \mathrm{~cm}^{-1}$ and $1835-1585 \mathrm{~cm}^{-1}$. The strong bands between 4000 and $3025 \mathrm{~cm}^{-1}$ have been attributed to lipids and moisture; bands between 3025 and $2800 \mathrm{~cm}^{-1}$ to proteins and the low intensity bands between 1835 and $1585 \mathrm{~cm}^{-1}$ are resulting from proteins and, again, lipids.

In the second part of chemometrics analysis, Coomans plots for the classification of pure WF-4 vs. WF/BF blends and blends of BF-1 were constructed considering information from the selected regions of $4000-3025 \mathrm{~cm}^{-1}$, $3025-2800 \mathrm{~cm}^{-1}$ and $1835-1585 \mathrm{~cm}^{-1}$ only (Figs. 4, 5). From the figures, it is clear that pure WF-4 and BF blends are not well separated when only using spectral information from the selected three regions. However, excellent classifications between pure WF-4 and its blends were obtained. This means that no samples for pure and adulterated wheat flours were incorrectly located into the wrong group. Addition of just $1 \%$ of barley flours to wheat flour was already noticeable from the classification plots build using spectral information from the three most informative regions. From these results, it is clear that the FT-IR spectral regions that reflect the flour's molecular structures and specific functional groups are valuable for the assessment of WF adulterations.

SIMCA analyses were performed individually using the spectral information from the three most discriminative regions to distinguish pure WFs from blends (Fig. S5, Supplementary Material 5). From the obtained Coomans plots, it is clear that any of these three optimal regions can be used for the detection of WF adulterations.

\subsection{PLSR based on full and selected wavenumber regions spectra}

To establish a quantitative prediction model for the level of BF in WF, blends were investigated and the full spectral data were used for PLSR analysis. Calibration models were separately developed with PLSR and results were shown in Table 3. PLSR could extract significant information from complicated spectra by describing the major types of spectral variations and relating these to compositional information, in that way generating calibration models (Rohman and Man 2012; Borràs et al. 2015). Herein, random splitting of the training set was performed $100 \times$ and each time, $75 \%$ of the training objects were used for developing a PLSR model and $25 \%$ for prediction according to the cross-validation method. Crossvalidation assesses the data by excluding selected samples from the regression model and then creating a model using the remaining samples. The model is being assessed using the samples excluded from the model and the error values for the predicted inspections are calculated. Next, new samples are then left out from the model set and a new model is built. This 
(a)

Sample Distances

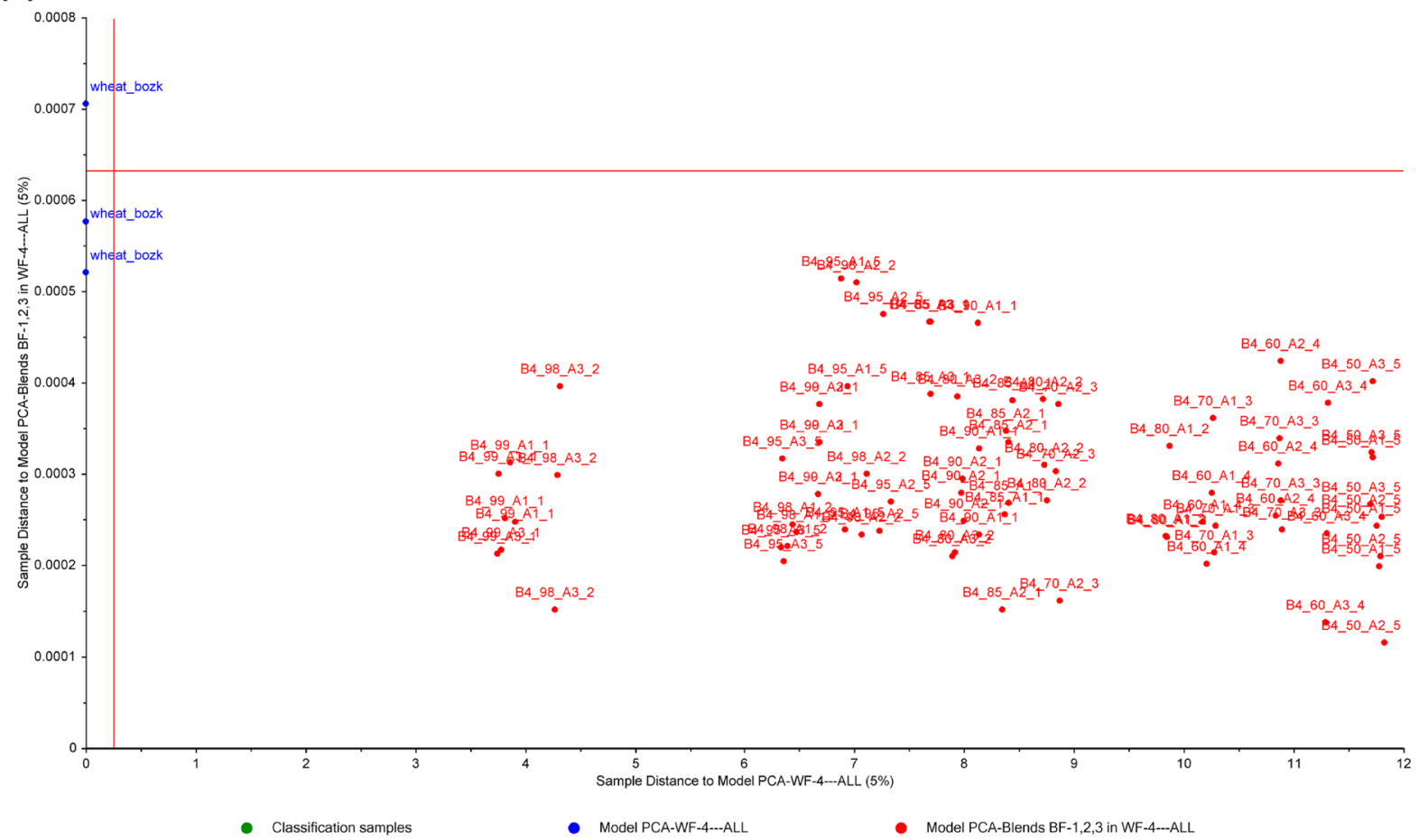

(b)

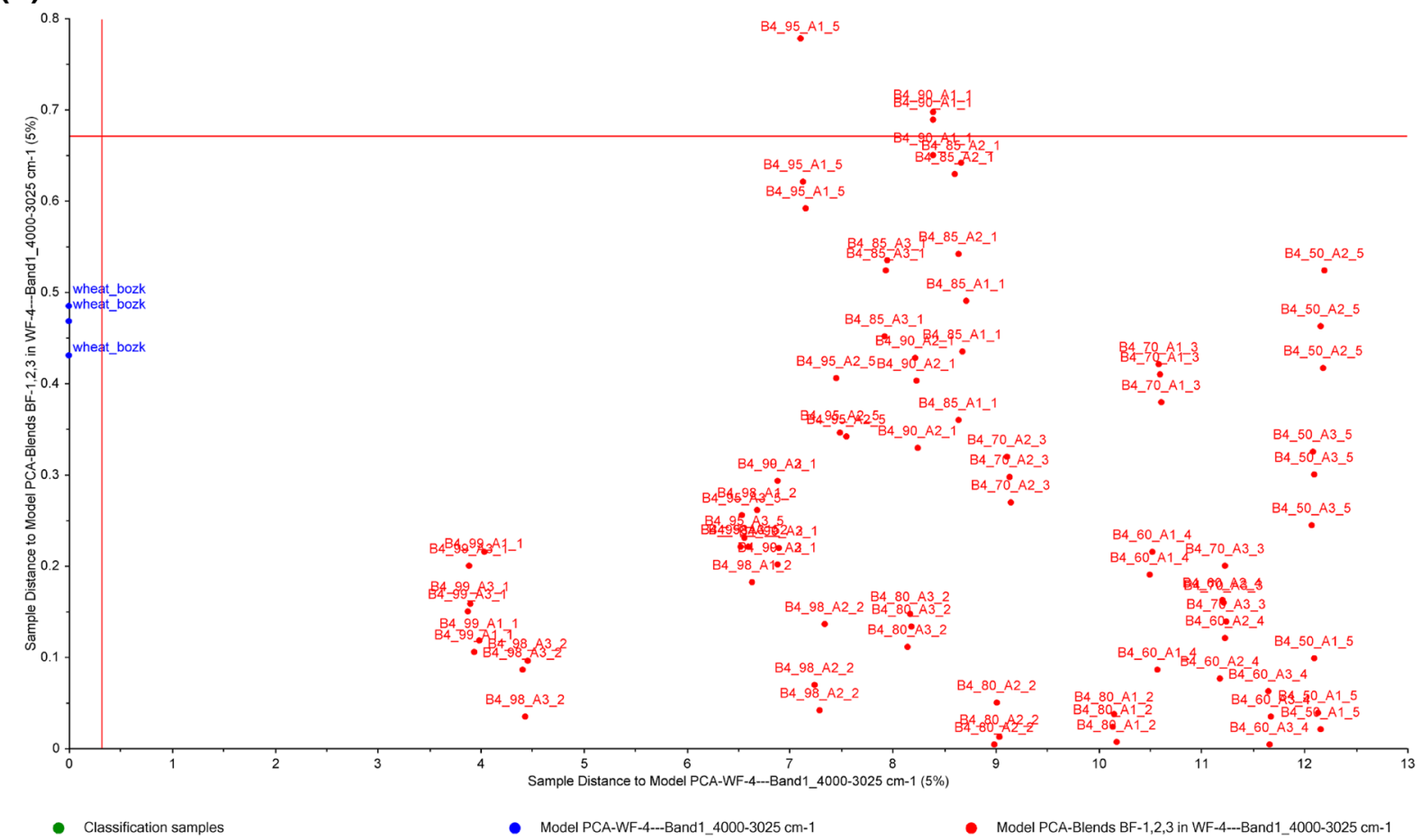

Fig. 4 SIMCA plots in the regions of a $4000-450 \mathrm{~cm}^{-1}$, b band-1 4000-3025 $\mathrm{cm}^{-1}$, c band-2 3025-2800 $\mathrm{cm}^{-1}$ and d band-9 1835$1585 \mathrm{~cm}^{-1}$ for pure WF-4 samples and blends of WF-4 with all barley flours $(B F-1, B F-2, B F-3)$. $W F$ wheat flour, $B F$ barley flour, $O F$ oat flour, $R F$ rye flour, $T F$ triticale flour, SIMCA soft independent modeling of class analogies, $P C A$ principle component analysis 
(c)

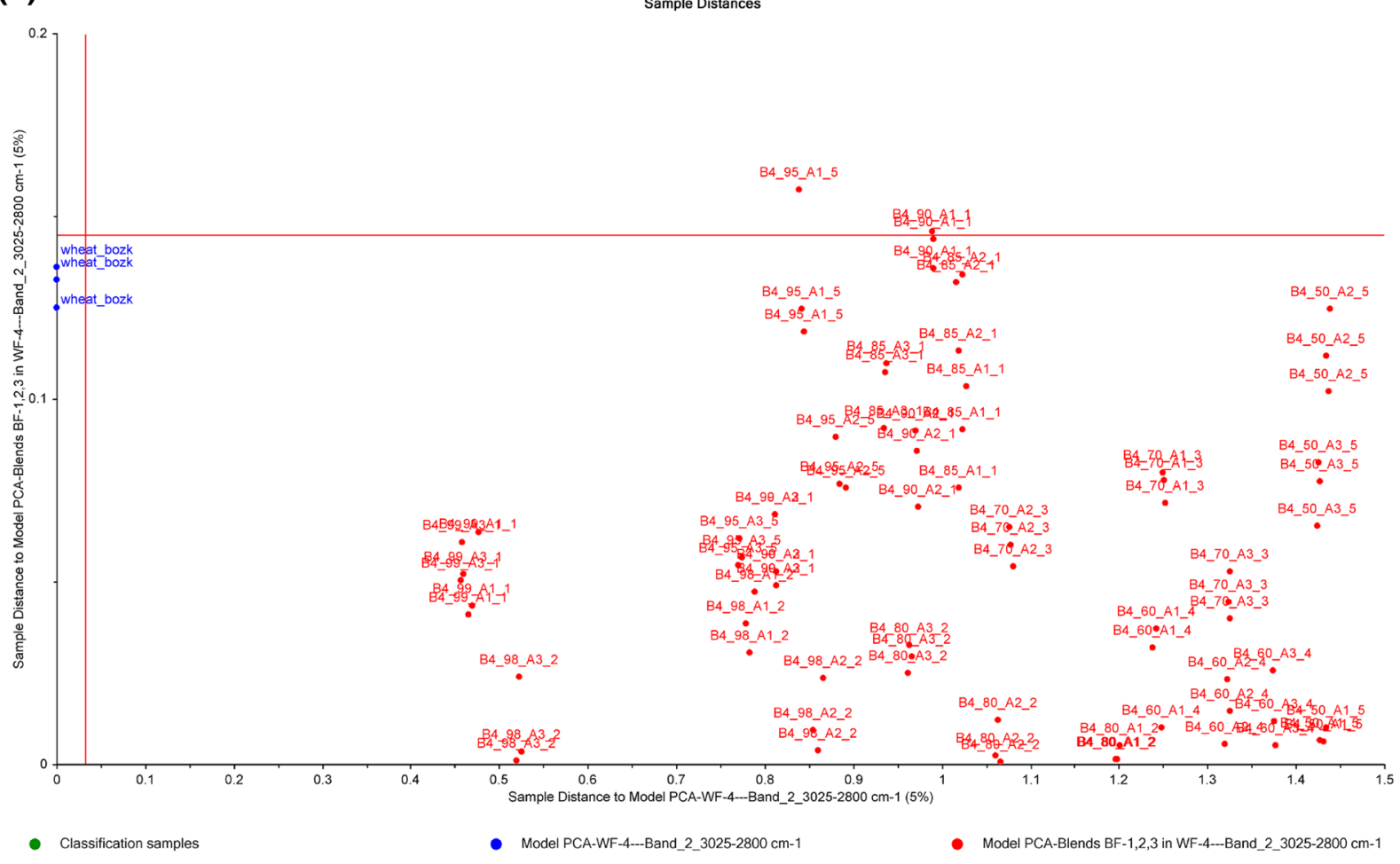

(d)

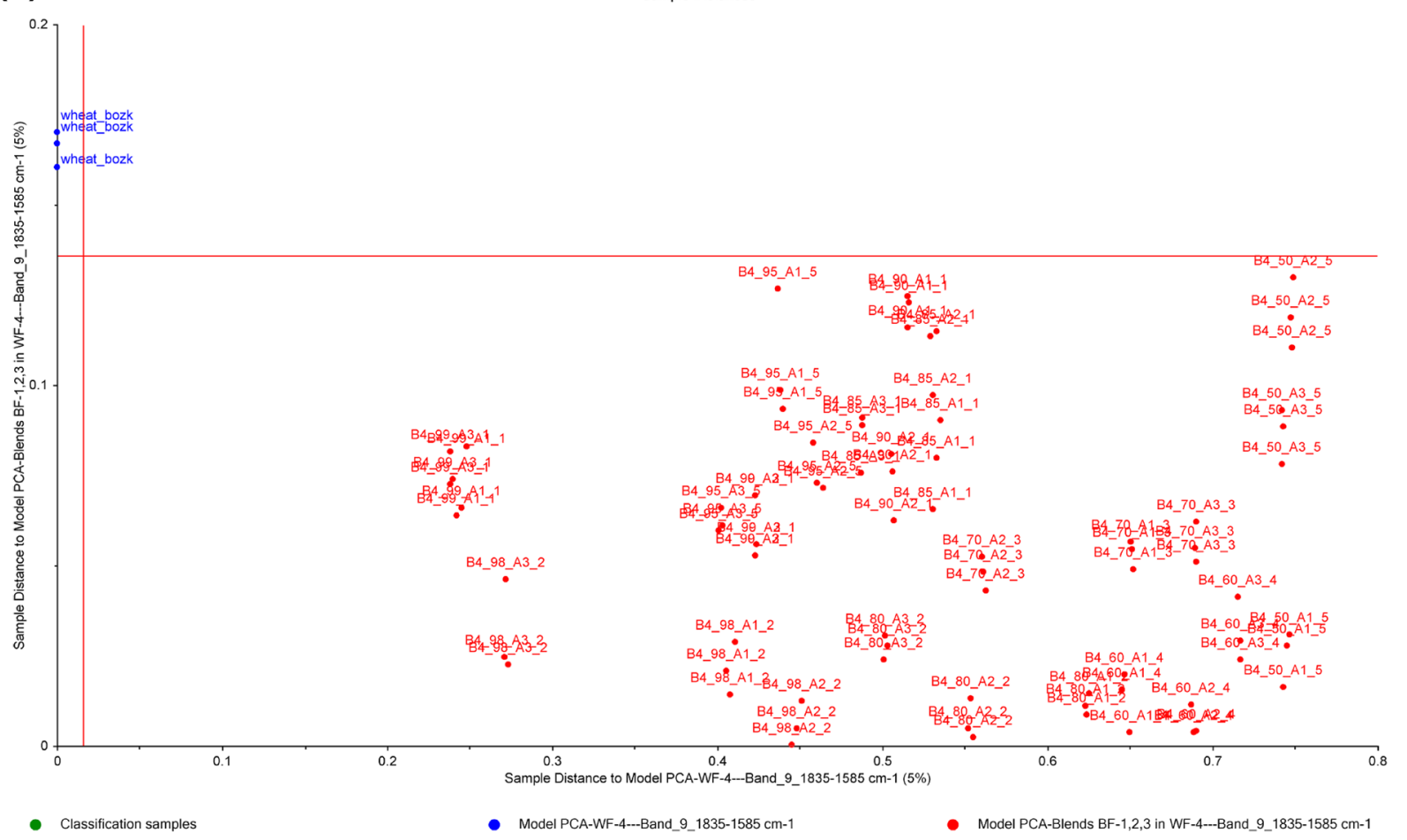

Fig. 4 (continued) 
(a)

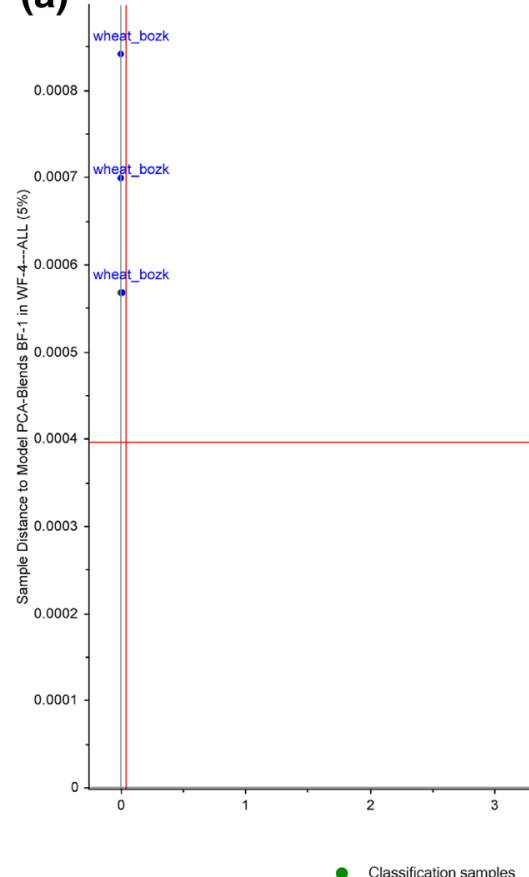

- Classification samples
Sample Distances
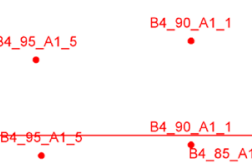

$B 480 A 12$

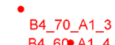

$4600-A 1$

B4_50_A1_5

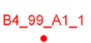

B4_99_A1_1

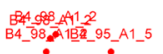

B4_BP4_P5_A1_1

B4_85_A1_1

B4_70_A1_3

B4 $800^{84}+62-11-4$

-

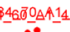

(b)

Sample Distances

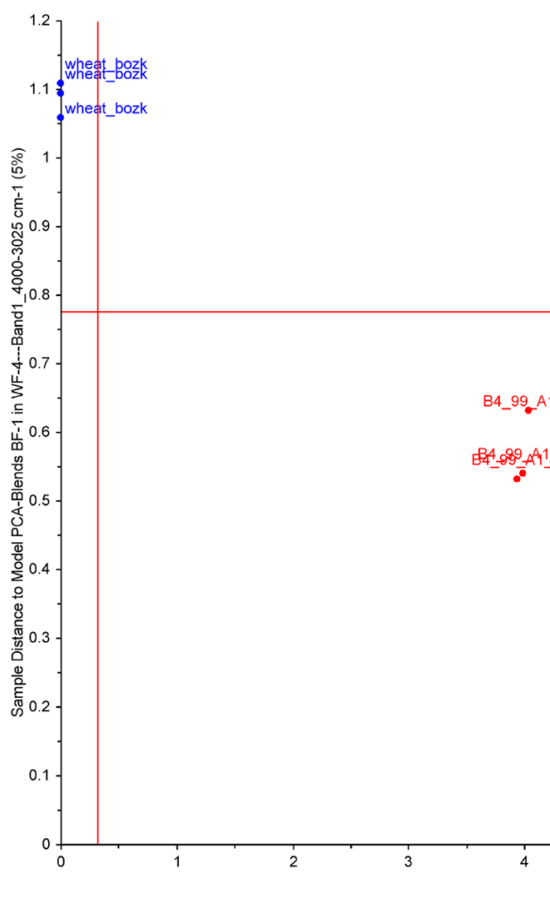

B4_99.A1_

B4-989A A1 - 1

B4_95_A1_5 $\begin{aligned} & \text { B4_98-A1 }-1 \\ & \text { B4_99 -A1_1 }\end{aligned}$

B4_95_A1_5
B4_93_A1_5

B4_85_A1_1

B4_85_A1_1

$\cdot$

B4_85_A1_1

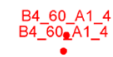

B.
$-60-A 1-4$
-

98_A1_2

B4_98 - $10_{-}{ }^{\circ}$

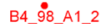

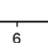

Sample Distance to Model PCA-WF-4---Band1_-4000-3025 cm-1 (5\%)

- Classification samples

- Model PCA-WF-4---Band1_4000-3025 cm-1

- Model PCA-Blends BF-1 in WF-4---Band1_4000-3025 cm-1

Fig. 5 SIMCA plots in the regions of a $4000-450 \mathrm{~cm}^{-1}$, b band-1 4000-3025 cm $\mathrm{cm}^{-1}$, c band-2 3025-2800 $\mathrm{cm}^{-1}$ and d band-9 1835 $1585 \mathrm{~cm}^{-1}$ for pure WF-4 samples and blends of WF-4 with BF-1.
[WF wheat flour, $B F$ barley flour, $O F$ oat flour, $R F$ rye flour, $T F$ triticale flour, SIMCA soft independent modeling of class analogies, $P C A$ principle component analysis] 
(c)

Sample Distances

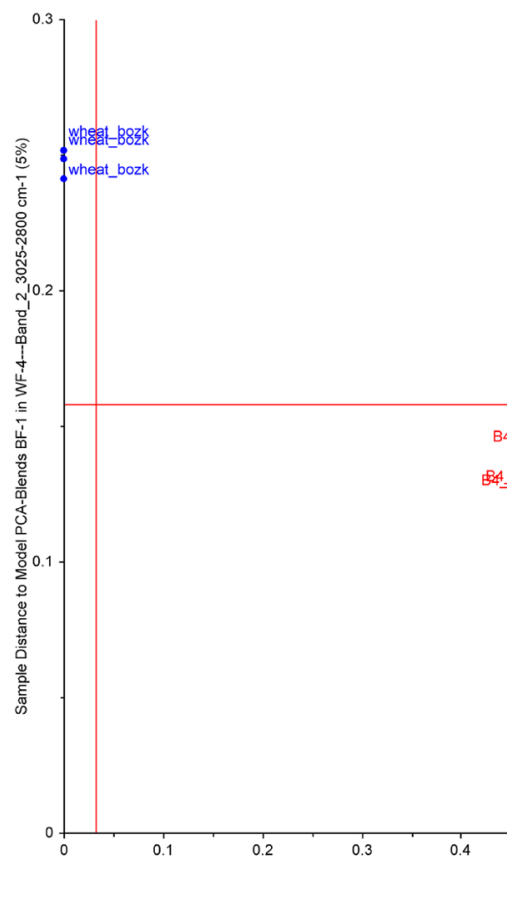

B4_-99.A1_-1

$-999-A+1$

- Classification samples

B4_-95_-A1_5 $\quad$ B4_-36-A1 1

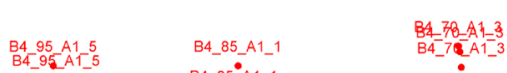

B4-85.A1_1

B4_-85_A1_1

85-A1 1

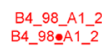

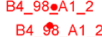

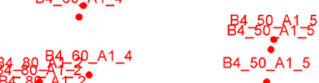

$\begin{array}{lllll}0.8 & 0.9 & 1 & 1.1 & 1.2\end{array}$

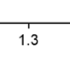

$1.4 \longrightarrow 1.5$

- Model PCA-Blends BF-1 in WF-4---Band_2_3025-2800 cm-1

(d)

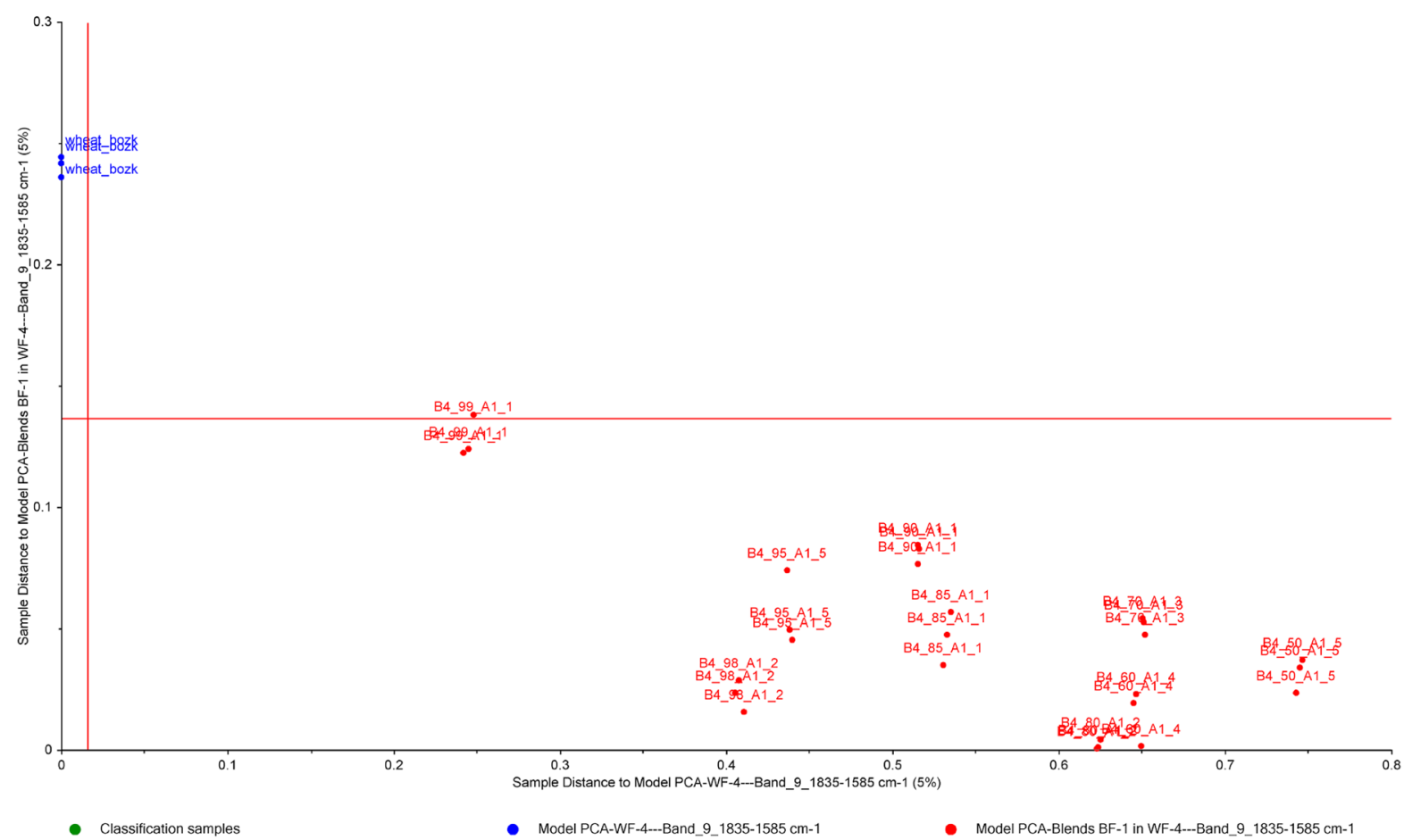

Fig. 5 (continued) 
Table 3 Results of the PLSR models for the mixtures of barley flours in wheat flours using the region of 4000$450 \mathrm{~cm}^{-1}$

\begin{tabular}{|c|c|c|c|c|c|c|c|c|c|}
\hline \multirow[t]{2}{*}{ Sample sets } & \multirow[t]{2}{*}{$\mathrm{N}$} & \multicolumn{4}{|c|}{ Calibration set } & \multicolumn{4}{|c|}{ Validation set } \\
\hline & & Slope & Offset & RMSEC & $\mathrm{R}$-square & Slope & Offset & RMSECV & R-square \\
\hline \multicolumn{10}{|c|}{ BF-1 $(0-50 \%)$} \\
\hline WF-1 & 10 & 0.9972 & 0.0484 & 0.8787 & 0.9972 & 0.9973 & 0.0393 & 0.9489 & 0.9970 \\
\hline WF-2 & 10 & 0.9995 & 0.0093 & 0.3848 & 0.9995 & 0.9990 & 0.0107 & 0.4188 & 0.9992 \\
\hline WF-3 & 10 & 0.9959 & 0.0761 & 1.1783 & 0.9945 & 0.9934 & 0.0761 & 1.1783 & 0.9945 \\
\hline WF-4 & 10 & 0.9996 & 0.0074 & 0.3448 & 0.9996 & 0.9996 & 0.0111 & 0.3647 & 0.9994 \\
\hline \multicolumn{10}{|c|}{ BF-2 (0-50\%) } \\
\hline WF-1 & 10 & 0.9945 & 0.0946 & 1.2293 & 0.9945 & 0.9935 & 0.0907 & 1.3471 & 0.9943 \\
\hline WF-2 & 10 & 0.9990 & 0.0178 & 0.5335 & 0.9990 & 0.9990 & 0.0248 & 0.5608 & 0.9991 \\
\hline WF-3 & 10 & 0.9979 & 0.0370 & 0.7682 & 0.9979 & 0.9978 & 0.0412 & 0.8158 & 0.9976 \\
\hline WF-4 & 10 & 0.9970 & 0.0527 & 0.9174 & 0.9970 & 0.99968 & 0.0325 & 0.9924 & 0.9969 \\
\hline \multicolumn{10}{|c|}{ BF-3 (0-50\%) } \\
\hline WF-1 & 10 & 0.999 & 0.01126 & 0.4240 & 0.9993 & 0.9991 & 0.0089 & 0.4598 & 0.9992 \\
\hline WF-2 & 10 & 0.9948 & 0.0906 & 1.2030 & 0.9948 & 0.9938 & 0.1101 & 1.2720 & 0.9937 \\
\hline WF-3 & 10 & 0.9995 & 0.0079 & 0.3548 & 0.9995 & 0.9992 & 0.0099 & 0.3920 & 0.9994 \\
\hline WF-4 & 10 & 0.9935 & 0.1121 & 1.3380 & 0.9935 & 0.9971 & 0.0781 & 1.5004 & 0.9926 \\
\hline
\end{tabular}

$W F$ wheat flour, $B F$ barley flour, $O F$ oat flour, $R F$ rye flour, $T F$ triticale flour, $R M S E C$ root mean square error of calibration, $R M S E C V$ root mean square error of cross validation procedure is repeated until all samples in the PLSR have been left out once (Arslan and Çă̆lar 2019; Karuk Elmas et al. 2019; Kenar et al. 2019). After predicting all the observations using the cross-validation method, the R-square, RMSEC and RMSECV values were computed (Table 3 ). The quantitative analysis, PLSR plots for the blends of BF and WF, based on the selected wavenumbers are presented in Fig. S6 (Supplementary Material 6).

Table 3 shows that a good linearity is obtained in the plots of monitored BF levels vs. predicted BF levels. The slope values were highly close to 1 and $\mathrm{R}^{2}$ values were at least 0.9926 . The robustness of the calibration and validation models is described by the $\mathrm{R}^{2}$, RMSEC and RMSECV. RMSEC were obtained in the range $0.34-1.34 \%$ and RMSECV results in the range $0.36-1.50 \%$. The difference between RMSEC and RMSECV were insignificant, furthermore these values are comparable and around $0.50 \%$, which is lower than the $1 \%$ margin associated with the official methods (Cocchi et al. 2006). The current FT-IR method combined with multivariate data analysis techniques like PLSR allows rapid detection of BF in WF. According to the statistical results of PLSR, accurate quantification of the BF is possible at levels $>0.3 \%$. Therefore, the results show that the models built are useful not only for grossly fraudulent cases, but also for detecting WF adulteration with $\mathrm{BF}$ at low adulterant levels.

\section{Conclusion}

Rapid, non-destructive and reliable methods for detecting of WF adulteration were developed based on the combination of FT-IR spectroscopy and chemometrics. The results of this study show that WF can be discriminated from other flours by comparison of their spectral fingerprints. SIMCA models provided an excellent classification of pure $\mathrm{WF}$, and the limit for the detection of BF in WF was below 1\%. Furthermore, a total of $98.25 \%$ of the pure flours were correctly classified on the basis of their origin in calibration and in cross-validation by LDA models. The peaks and peak groups of the selected spectral regions combined with supervised SIMCA and LDA models proved to be capable to provide excellent classifications and discriminations. Under the optimal conditions, the proposed PLSR models are linear $\left(R^{2}>0.99\right)$. The best prediction abilities for PLSR were obtained with RMSEC and RMSECV between $0.34-1.34 \%$ and $0.36-1.50 \%$, respectively. Consequently, the developed PLSR is able to quantify the content of the most likely adulterant barley flour at levels $<0.30 \%$ in an unknown WF sample.

Acknowledgements The financial supports from the Scientific Research Project Center of Karamanoglu Mehmetbey University (No: 04-M-19 and 05-M-19), the Scientific Research Project Center of Ankara University and TUBITAK-ARDEB (No: $116 Z 159$ for providing the financial support to gain access to Unscrambler ${ }^{\circledR}$ X10.4 program) and the TUBITAK-BIDEB (2219-Research Fellowship Program) are gratefully acknowledged. 


\section{Compliance with ethical standards}

Conflict of interest The authors declare that they have no further conflict of interest.

\section{References}

American Association of Cereal Chemists (1989) Approved methods of the American Association of Cereal Chemists. American Association of Cereal Chemists, St. Paul

Akubor PI, Badifu GIO (2004) Chemical composition, functional properties and baking potential of African breadfruit kernel and wheat flour blends. Int J Food Sci Technol 39:223-229. https://doi.org/10 .1046/j.0950-5423.2003.00768.x

Amir RM, Anjum FM, Khan MI, Khan MR, Pasha I, Nadeem M (2013) Application of Fourier transform infrared (FTIR) spectroscopy for the identification of wheat varieties. J Food Sci Technol 50:1018 1023. https://doi.org/10.1007/s13197-011-0424-y

Arslan FN, Çağlar F (2019) Attenuated total reflectance-Fourier transform infrared (ATR-FTIR) spectroscopy combined with chemometrics for rapid determination of cold-pressed wheat germ oil adulteration. Food Anal Methods 12:355-370

Ballabio D, Consonni V (2013) Classification tools in chemistry. Part 1: linear models. PLS-DA. Anal Methods 5:3790-3798. https://doi. org/10.1039/c3ay40582f

Borràs E, Ferré J, Boqué R, Mestres M, Aceña L, Busto O (2015) Data fusion methodologies for food and beverage authentication and quality assessment-a review. Anal Chim Acta 891:1-14. https://doi. org/10.1016/j.aca.2015.04.042

Carbonaro M, Maselli P, Dore P, Nucara A (2008) Application of Fourier transform infrared spectroscopy to legume seed flour analysis. Food Chem 108:361-368. https://doi.org/10.1016/j.foodc hem.2007.10.045

Cocchi M, Foca G, Lucisano M, Marchetti A, Pagani MA, Tassi L, Ulrici A (2004) Classification of cereal flours by chemometric analysis of MIR spectra. J Agric Food Chem 52:1062-1067. https://doi. org/10.1021/jf034441o

Cocchi M, Durante C, Foca G, Marchetti A, Tassi L, Ulrici A (2006) Durum wheat adulteration detection by NIR spectroscopy multivariate calibration. Talanta 68:1505-1511. https://doi.org/10.1016/j. talanta.2005.08.005

Cozzolino D (2015) The role of vibrational spectroscopy as a tool to assess economically motivated fraud and counterfeit issues in agricultural products and foods. Anal Methods 7:9390-9400. https://doi. org/10.1039/C5AY01792K

Cozzolino D, Roumeliotis S, Eglinton J (2013) Prediction of starch pasting properties in barley flour using ATR-MIR spectroscopy. Carbohyd Polym 95:509-514. https://doi.org/10.1016/j.carbp ol.2013.03.001

Czaja T, Mazurek S, Szostak R (2016) Quantification of gluten in wheat flour by FT-Raman spectroscopy. Food Chem 211:560-563. https ://doi.org/10.1016/j.foodchem.2016.05.108

Deng DH, Xu L, Ye ZH, Cui HF, Cai CB, Yu XP (2012) FTIR spectroscopy and chemometric class modeling techniques for authentication of chinese sesame oil. J Am Oil Chem Soc 89:1003-1009. https:// doi.org/10.1007/s11746-011-2004-8

Dong X, Sun X (2013) A case study of characteristic bands selection in near-infrared spectroscopy: Nondestructive detection of ash and moisture in wheat flour. J Food Meas Charact 7:141-148. https:// doi.org/10.1007/s11694-013-9149-0

Ellis DI, Brewster VL, Dunn WB, Allwood JW, Golovanov AP, Goodacre R (2012) Fingerprinting food: current technologies for the detection of food adulteration and contamination. Chem Soc Rev 41:5706. https://doi.org/10.1039/c2cs35138b

Ferrão MF, Davanzo CU (2005) Horizontal attenuated total reflection applied to simultaneous determination of ash and protein contents in commercial wheat flour. Anal Chim Acta 540:411-415. https:// doi.org/10.1016/j.aca.2005.03.038

Fragaki G, Spyros A, Siragakis G, Salivaras E, Dais P (2005) Detection of extra virgin olive oil adulteration with lampante olive oil and refined olive oil using nuclear magnetic resonance spectroscopy and multivariate statistical analysis. J Agric Food Chem 53:2810-2816. https://doi.org/10.1021/jf040279t

Georget DMR, Belton PS (2006) Effects of temperature and water content on the secondary structure of wheat gluten studied by FTIR spectroscopy. Biomacromolecules 7:469-475. https://doi.org/10.1021/ bm050667j

González-Martín MI, Wells Moncada G, González-Pérez C, Zapata San Martín N, López-González F, Lobos Ortega I, Hernández-Hierro JM (2014) Chilean flour and wheat grain: tracing their origin using near infrared spectroscopy and chemometrics. Food Chem 145:802-806. https://doi.org/10.1016/j.foodchem.2013.08.103

Guo XX, Hu W, Liu Y, Gu DC, Sun SQ, Xu CH, Wang XC (2015) Rapid analysis and quantification of fluorescent brighteners in wheat flour by tri-step infrared spectroscopy and computer vision technology. J Mol Struct 1099:393-398. https://doi.org/10.1016/j.molst ruc.2015.06.081

Gurdeniz G, Ozen B, Tokatli F (2008) Classification of Turkish olive oils with respect to cultivar, geographic origin and harvest year, using fatty acid profile and mid-IR spectroscopy. Eur Food Res Technol 227:1275-1281. https://doi.org/10.1007/s00217-008-0845-7

Hernández OM, Fraga JMG, Jiménez AI, Jiménez F, Arias JJ (2014) Characterization of toasted cereal flours from the Canary Islands (gofios). Food Chem 151:133-140. https://doi.org/10.1016/j.foodc hem.2013.11.039

Hong E, Lee SY, Jeong JY, Park JM, Kim BH, Kwon K, Chun HS (2017) Modern analytical methods for the detection of food fraud and adulteration by food category. J Sci Food Agric 97:3877-3896. https:// doi.org/10.1002/jsfa.8364

Kaddour AA, Mondet M, Cuq B (2008) Application of two-dimensional cross-correlation spectroscopy to analyse infrared (MIR and NIR) spectra recorded during bread dough mixing. J Cereal Sci 48:678-685. https://doi.org/10.1016/j.jcs.2008.03.001

Karuk Elmas ŞN, Arslan FN, Akin G, Kenar A, Janssen HG, Yilmaz I (2019) Synchronous fluorescence spectroscopy combined with chemometrics for rapid assessment of cold-pressed grape seed oil adulteration: qualitative and quantitative study. Talanta 196:22-31. https://doi.org/10.1016/j.talanta.2018.12.026

Kenar A, Çiçek B, Arslan FN, Akin G, Karuk Elamas SN, Yilmaz I (2019) Electron impact-mass spectrometry fingerprinting and chemometrics for rapid assessment of authenticity of edible oils based on fatty acid profiling. Food Anal Methods 12:1369-1381

Lohumi S, Lee S, Lee H, Cho BK (2015) A review of vibrational spectroscopic techniques for the detection of food authenticity and adulteration. Trends Food Sci Technol 46:85-98. https://doi.org/10.1016/j. tifs. 2015.08.003

Moroi A, Vartolomei N, Aruş A, Nistor ID, Lazar IM (2011) Prediction of the ash content of wheat flours using spectral and chemometric methods. Food Technol 35:33-45. https://doi.org/10.1631/jzus.2005. A0643

Rohman A, Man YBC (2012) The chemometrics approach applied to FTIR spectral data for the analysis of rice bran oil in extra virgin olive oil. Chemom Intell Lab Syst 110:129-134. https://doi. org/10.1016/j.chemolab.2011.10.010

Rohman A, Man YBC, Yusof FM (2014) The use of FTIR spectroscopy and chemometrics for rapid authentication of extra virgin olive oil. J Am Oil Chem Soc 91:207-213. https://doi.org/10.1007/s1174 6-013-2370-5 
Saucedo-Hernández Y, Lerma-García MJ, Herrero-Martínez JM, RamisRamos G, Jorge-Rodríguez E, Simí-Alfonso EF (2011) Classification of pumpkin seed oils according to their species and genetic variety by attenuated total reflection Fourier-transform infrared spectroscopy. J Agric Food Chem 59:4125-4129. https://doi. org/10.1021/jf104278g

Savitzky A, Golay MJE (1964) Smoothing and differentiation of data by simplified least squares procedures. Anal Chem 36:1627-1639. https ://doi.org/10.1021/ac60214a047

Su W, Sun D (2016) Facilitated wavelength selection and model development for rapid determination of the purity of organic spelt (Triticum spelta L.) flour using spectral imaging. Talanta 155:347-357. https ://doi.org/10.1016/j.talanta.2016.04.041

Su W-H, Sun D-W (2017) Fourier transform infrared and Raman and hyperspectral imaging techniques for quality determinations of powdery foods: a review. Compr Rev Food Sci Food Saf 17:104-122. https://doi.org/10.1111/1541-4337.12314
Sujka K, Koczoń P, Ceglińska A, Reder M, Ciemniewska-Zytkiewicz H (2017) The application of FT-IR spectroscopy for quality control of flours obtained from polish producers. J Anal Methods Chem. https ://doi.org/10.1155/2017/4315678

Wang N, Zhang X, Yu Z, Li G, Zhou B (2014) Quantitative analysis of adulterations in oat flour by ft-nir spectroscopy, incomplete unbalanced randomized block design, and partial least squares. J Anal Methods Chem 393596:1-5. https://doi.org/10.1155/2014/393596

Ziegler JU, Leitenberger M, Longin CFH, Würschum T, Carle R, Schweiggert RM (2016) Near-infrared reflectance spectroscopy for the rapid discrimination of kernels and flours of different wheat species. J Food Compos Anal 51:30-36. https://doi.org/10.1016/j. jfca.2016.06.005

Publisher's Note Springer Nature remains neutral with regard to jurisdictional claims in published maps and institutional affiliations. 